\title{
Resonant Frequency of Tunable Microstrip Ring Antenna Printed on Isotropic or Uniaxially Anisotropic Substrate
}

\author{
Sami Bedra ${ }^{1^{*}}$, Siham Benkouda ${ }^{2}$, Mounir Amir $^{1}$, and Tarek Fortaki $^{1}$ \\ ${ }^{1}$ Electronics Department, University of Batna, Algeria. \\ ${ }^{2}$ Electronics Department, University of Constantine, Algeria. \\ *corresponding author, E-mail: bedra_sami@yahoo.fr
}

\begin{abstract}
In this study, the resonant frequency of annular ring microstrip resonator with uniaxial anisotropic substrate and air gap layer is analyzed. The cavity model for simple ring microstrip antenna is extended with some modifications for the tunable geometry taking into account the anisotropy in the layer. The theoretical resonant frequency results are in very good agreement with the experimental results reported elsewhere. The air gap tuning effect on the resonant characteristics is also investigated for fundamental and higher order modes.
\end{abstract}

\section{Introduction}

During the last three decades, a considerable number of papers have been published on the performance and applications of microstrip patch antennas. These patch antennas possess many desirable features, that make this type of antennas useful for many applications in radar and wireless communication systems. Various patch configurations implemented on different types of substrates have been tested and investigated. In practice, it was found that the choice of the substrate material is of a great importance and plays a significant role in achieving the optimum radiation characteristics of the antenna [1].

Annular ring microstrip antennas, because of their flexibility for producing dual frequency treatment [2] and advantages for using in medical applications [3] are interesting to many researchers. This type of printed antenna can have a broader bandwidth than other shape of patch antenna by a proper choice of dimensions and the mode of operation. Because of these advantages several studies have been done on the annular ring patch antennas [2-6]. Furthermore, ring resonators have found applications in circulators, hybrid junction filters and other microwave devices [7]. Several articles on ring patch on uniaxial substrates have been recently published [7-9].

The circular ring has been analyzed extensively using the cavity model [4, 10-12], generalized transmission line model [13], analysis in the Fourier-Hankel transform domain [5], and the method of matched asymptotic expansion [14]. The cavity model has been chosen as a simple alternative to analyze and predict the behavior of microstrip ring antennas. Furthermore, some modifications are made to account for fringe fields, dispersion effects, and losses by calculating effective dimensions, effective relative permittivity, and effective loss tangent, respectively.

The aim of this work is to perform an accurate and efficient analysis of annular-ring microstrip antennas on double layer, as well as to perform the analyses for annular ring microstrip antennas on a single layer substrate and on a tunable substrate, as particular cases.

\section{Antenna configuration and design}

The tunable microstrip ring antenna structure is shown in Fig.1. The resonant behavior of the antenna is independent of the feed so that the feed was not taken into account in the analysis.

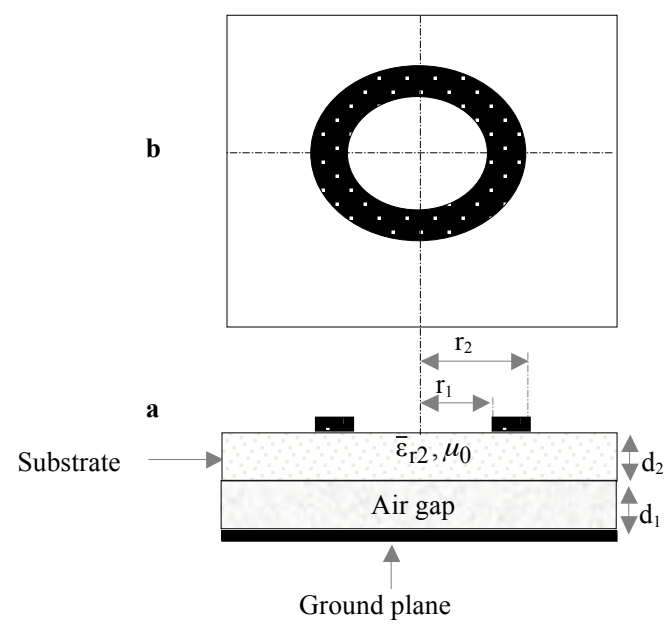

Figure 1: Geometry of a tunable microstrip ring antenna.

a- Side view

b- Top view

In order to calculate the resonant frequency, the original two-layered structure is reduced to a single layered one having an equivalent relative permittivity $\varepsilon_{e q}$.

Then the resonant frequency is determined for the equivalent single layered structure as:

$$
f_{r, m n}=\frac{k v_{0}}{2 a \sqrt{\varepsilon_{e q}}}
$$

where $v_{0}$ is the velocity of light in free space, $k=2 n /\left(r_{1}+r_{2}\right)$ is the wave number, $r_{1}, r_{2}$ the ring radiuses, 
and the integer $n$ denotes the azimuthal variation. $\varepsilon_{e q}$ is the equivalent permittivity of the single layered structure was obtained from the cavity analysis by [15]

$$
\varepsilon_{e q}=\frac{\varepsilon_{r 2}\left(d_{1}+d_{2}\right)}{\left(d_{2}+\varepsilon_{r 2} d_{1}\right)}
$$

For $\mathrm{TM}_{\mathrm{mn}}$. modes, the resonant frequency for a ring resonator can be calculated by taking in to account the effect of fringing fields, using:

$$
f_{r}=\frac{k v_{0}}{2 \pi w \sqrt{\varepsilon_{e f f}}}
$$

where $v_{0}$ is the velocity of light in free space, $k=2 n /\left(r_{1}+r_{2}\right)$ is the wave number, $r_{1}, r_{2}$ the ring radiuses, $\varepsilon_{\text {eff }}$ is the effective dielectric constant for a microstrip line of strip width $w=r_{2}-r_{l}$.

To account for the fact that small fraction of the field exists outside the dielectric; it is customary to use effective permittivity $\varepsilon_{\text {eff }}$ in place of $\varepsilon_{\text {req }}$

$$
\varepsilon_{e f f}=\frac{1}{2}\left[\left(\varepsilon_{r e q}+1\right)+\left(\varepsilon_{r e q}-1\right)\right]\left(1+\frac{10 d}{w}\right)^{\frac{1}{2}}
$$

The resonant frequency of the ring resonator can be predicted more accurately using the planar wave guide model [16] for microstrip line. In this model, the width of ring is taken as the width of parallel conducting plates spaced a distance $d$ apart and separated by medium of relative permittivity $\varepsilon_{e f f}$. The microstrip of width $w$ and the planar waveguide model will have the same quasi-static characteristic impedance $Z_{0}$. The modified values of the inner and outer radii, taking into account the fringing fields along the curved edges of ring, may be written [10]

$$
\begin{aligned}
& r_{2 e}=r_{2}+\left[w_{e}(f)-w\right] / 2 \\
& r_{1 e}=r_{1}-\left[w_{e}(f)-w\right] / 2
\end{aligned}
$$

where

$$
\begin{aligned}
& w_{e}(f)=w+\frac{w_{e}(0)-w}{\left(f / f_{p}\right)^{2}} \\
& w_{e}(0)=\frac{120 \pi d}{Z_{0} \sqrt{\varepsilon_{e f f}}} \\
& f_{p}=\frac{Z_{0}}{2 \mu d}
\end{aligned}
$$

a pair of empirical formulas for the modified radii, sufficient for many enginerring purposes, are given by [17]

$$
\begin{aligned}
& r_{1 e}=r_{1}-3 h / 4 \\
& r_{2 e}=r_{2}+3 h / 4
\end{aligned}
$$

where $r_{l e}$ and $r_{2 e}$ are the effective radii.

Now for the transformed structure, the effective dielectric constant is determined and the modified eigen values are obtained by solving the following characteristic equation:

$$
J_{n}^{\prime}\left(k r_{2 e}\right) Y_{n}^{\prime}\left(k r_{1 e}\right)-J_{n}^{\prime}\left(k r_{1 e}\right) Y_{n}^{\prime}\left(k r_{2 e}\right)=0
$$

where; $J_{n}$ and $Y_{n}$ are Bessel functions of the first and second kind (the prime denotes derivatives with respect to $x$ ), and order $n$, respectively for $k$ when the given values of $r_{l e}$ and $r_{2 e}$, the resonant frequency is determined from eq.(1).

For a given values of $r_{1 e}$ and $r_{2 e}$, of annular-ring patch, $r_{l e}$ and $r_{2 e}$, are calculated. After solving the eqn. (10), the $m n$-order mode resonant frequency may be predicted accurately from:

$$
f_{r m n}=\frac{\chi_{m n} v_{0}}{2 \pi w \sqrt{\varepsilon_{e f f}}}
$$

where $\operatorname{Re}\left\{k_{m n} r_{1}\right\}=\chi_{m n}$ is the real part of $\left(k_{m n} r_{l}\right)$,and denotes the root of the characteristic equation(10).

It should be pointed out that the correction to the resonant frequency (1) in formula (11) involves both the effective permittivity and the effective radii, what permits to obtain a good agreement between theory and experiment in the case of the annular ring antenna.

If we want to take the substrate uniaxial anisotropy into account, the relative dielectric permittivity $\varepsilon_{\mathrm{r}}$ will be replaced with the tensor $\varepsilon_{\mathrm{r}}=\operatorname{diag}\left(\varepsilon_{x}, \varepsilon_{x}, \varepsilon_{z}\right)$ where $\varepsilon_{x}$ and $\varepsilon_{z}$ are the relative dielectric permittivity along $x$ and $z$ axis, respectively.

- For the case of isotropic substrate with air gap, the effective dielectric constant $\varepsilon_{e q}$ is given in Eq.(2).

- For the case of uniaxially anisotropic substrate without air gap, $\varepsilon_{e q}$ given in [18] Eq. (2) is used to determine $d_{e}$, there resulting values are:

\begin{tabular}{|c|c|c|c|c|c|}
\hline \multirow{2}{*}{$\begin{array}{l}\frac{0}{8} \\
\sum\end{array}$} & \multirow[t]{2}{*}{$\varepsilon_{r 2}$} & \multirow{2}{*}{$\begin{array}{c}r_{l} \\
{[\mathrm{~cm}]}\end{array}$} & \multirow{2}{*}{$\begin{array}{c}\begin{array}{c}\text { Measured } f_{r} \\
\text { [GHz] }\end{array} \\
{[15]}\end{array}$} & \multicolumn{2}{|c|}{$\begin{array}{c}\text { Calculated } \\
\text { Frequencies } f_{r} \\
{[\mathrm{GHz}]}\end{array}$} \\
\hline & & & & [4] & $\begin{array}{l}\text { Our } \\
\text { results }\end{array}$ \\
\hline $\mathrm{TM}^{11}$ & 2.32 & 2.5 & 0.877 & 0.878 & 0.875 \\
\hline $\mathrm{TM}^{21}$ & 2.32 & 2.5 & 1.722 & 1.723 & 1.732 \\
\hline $\mathrm{TM}^{31}$ & 2.32 & 2.5 & 2.517 & 2.515 & 2.556 \\
\hline $\mathrm{TM}^{11}$ & 2.32 & 3.5 & 0.626 & 0.623 & 0.621 \\
\hline
\end{tabular}

$$
\begin{aligned}
\varepsilon_{e} & =\varepsilon_{z} \\
d_{e} & =d \sqrt{\frac{\varepsilon_{x}}{\varepsilon_{z}}}
\end{aligned}
$$

\section{Results and discussion}

In order to confirm the computation accuracy of the approach described in the previous section, our numerical results are compared with those obtained from other works $[15,4]$ for different resonant modes of circular ring microstrip antenna.

Table 1: Comparison of measured and theoretical resonant frequencies for no gap case, $d_{1}=0, r_{2}=2 r_{1}$,

In order to check the accuracy of the model for twolayered case, in Table 2 our results are compared with 
experimental and theoretical values presented in previous work [15].

In Table 1, comparisons of the results with experimental values which were collected from different references [4] and [15] shows that the agreement of both models are good for TMn1 modes. But developed model by [4] was not extended for two-layered structure. In Table 2, the results of our model are compared with those of [15]. In this Table, we have also added the error values for our results as well as for the results taken from paper [20]. It is clear that our results are better than those of [20].

Table 2: Comparison of measured and theoretical resonant frequencies for, $r_{1}=35 \mathrm{~mm}, r_{2}=2 r_{1}, \varepsilon_{r 2}=2.32$.

\begin{tabular}{|c|c|c|c|c|c|c|}
\hline \multirow{2}{*}{$\frac{\Xi}{\Xi}$} & \multirow{2}{*}{$\sum_{i}^{\infty} \sum_{i}^{\infty}$} & \multicolumn{2}{|l|}{$\begin{array}{c}\text { Measured } \\
f_{r}[\mathrm{GHz}]\end{array}$} & \multicolumn{3}{|c|}{$\begin{array}{c}\text { Calculated Frequencies } \\
f_{r}[\mathrm{GHz}]\end{array}$} \\
\hline & & [15] & {$[20]$} & $\begin{array}{l}\text { Relative } \\
\text { errors \% }\end{array}$ & $\begin{array}{c}\text { Our } \\
\text { results }\end{array}$ & $\begin{array}{l}\text { Relative } \\
\text { errors \% }\end{array}$ \\
\hline \multirow{3}{*}{0} & $\mathrm{TM}^{11}$ & 0.626 & 0.622 & 0.64 & 0.621 & 0.80 \\
\hline & $\mathrm{TM}^{21}$ & 1.229 & 1.220 & 0.73 & 1.228 & 0.08 \\
\hline & $\mathrm{TM}^{31}$ & 1.800 & 1.793 & 0.39 & 1.814 & 0.78 \\
\hline \multirow[t]{3}{*}{0} & $\mathrm{TM}^{11}$ & 0.720 & 0.714 & 0.83 & 0.711 & 1.25 \\
\hline & $\mathrm{TM}^{21}$ & 1.415 & 1.405 & 0.71 & 1.407 & 0.57 \\
\hline & $\mathrm{TM}^{31}$ & 2.075 & 2.057 & 0.87 & 2.077 & 0.10 \\
\hline \multirow{3}{*}{1} & $\mathrm{TM}^{11}$ & 0.778 & 0.763 & 1.93 & 0.760 & 2.31 \\
\hline & $\mathrm{TM}^{21}$ & 1.516 & 1.498 & 1.19 & 1.505 & 0.73 \\
\hline & $\mathrm{TM}^{31}$ & 2.212 & 2.185 & 1.22 & 2.221 & 0.41 \\
\hline
\end{tabular}

Note that the relative error in Table 2 is defined by the following equation:

$$
\text { Relative errors } \%=\left(\left|\left(f_{\text {theo }}-f_{\text {meas }}\right)\right| / f_{\text {meas }}\right) * 100
$$

Figure. 2 show the resonant frequency against the air gap thickness for various inner and outer radii of the annular ring patch. It is seen that the operating frequency increases with the air layer thickness for a given value of patch size, however, it depends inversely on the patch size for a given air gap width $d_{l}$.

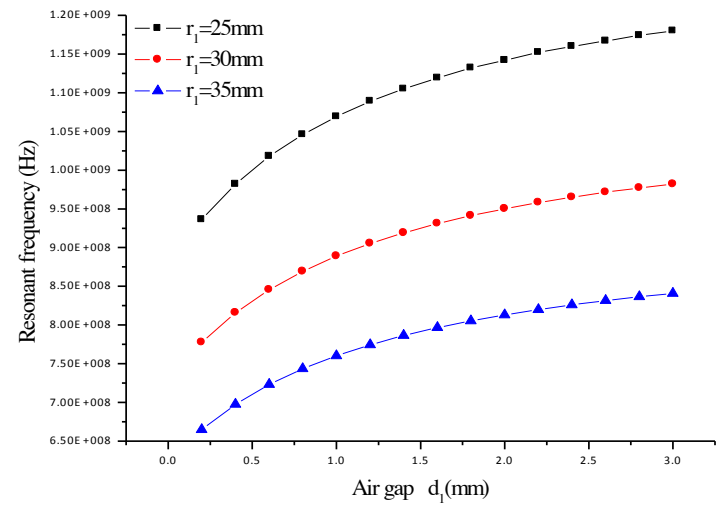

Figure 2: Resonant frequency versus air gap thickness for different values of patch radius, $r_{2}=35 \mathrm{~mm}, r_{2} / r_{1}=2$, $d_{2}=1.59 \mathrm{~mm}$, and $\varepsilon_{x}=\varepsilon_{z}=2.32$.

Next, the effect of uniaxial anisotropy on the resonant frequency is analyzed. The anisotropy ratio $(A R)$ is defined as $A R=\varepsilon_{x} / \varepsilon_{z}$
Figure. 3 depict the influence of the air gap thickness on the resonant frequency of an annular ring microstrip patch for three anisotropic dielectric substrates: boron nitride $\left(\varepsilon_{z}=3.4, \varepsilon_{x}=5.12\right)$ epsilam-10 $\left(\varepsilon_{z}=10.3, \varepsilon_{x}=13\right)$, and sapphire $\left(\varepsilon_{z}=11.6, \varepsilon_{x}=9.4\right)$. The substrate has thickness $d_{l}=1.59 \mathrm{~mm}$ and the air gap width is varied from $0 \mathrm{~mm}$ to $3 \mathrm{~mm}$.

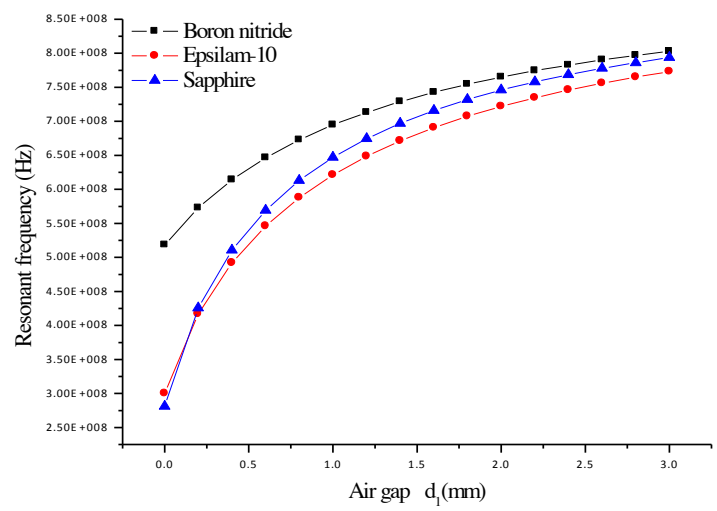

Figure 3: Resonant frequency versus air gap thickness for different anisotropic dielectric substrates, with $r_{2} / r_{1}=2$, and $d_{2}=1.59 \mathrm{~mm}$.

As it can be seen, the resonant frequency reduces considerably when the dielectric substrate changes from boron nitride to epsilam-10, and this is in contrast to what happens when the medium changes from epsilam-10 to sapphire. The obtained results show that when the permittivity $\varepsilon_{z}$ is changed and $\varepsilon_{x}$ remains constant, the resonant frequency changes drastically, on the other hand, we found a slight shift in the resonant frequency when the permittivity $\varepsilon_{x}$ is changed and $\varepsilon_{z}$ remains constant. These behaviors agree very well with those reported by [19]. Also it is observed that the resonant frequency increases with the air gap thickness.

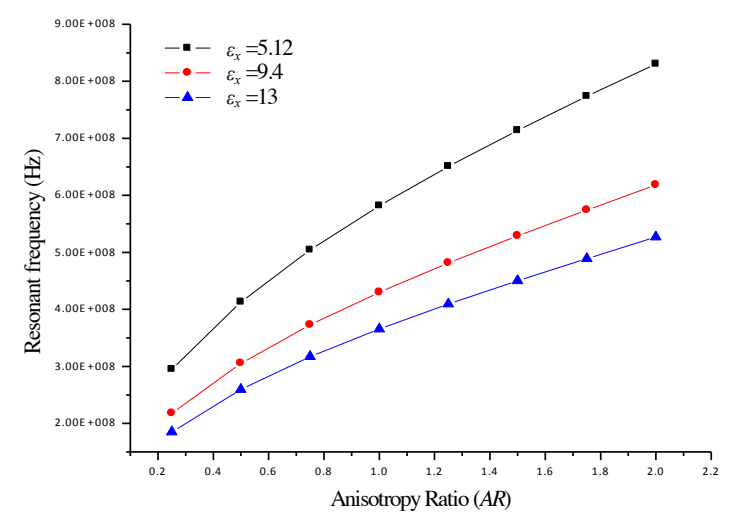

Figure 4: Resonant frequency versus anisotropy ratio $(A R)$ for different permittivity $\varepsilon_{x}$, with $r_{l}=25 \mathrm{~mm}, r_{2} / r_{l}=2$, $d_{2}=1.59 \mathrm{~mm}$, and $d_{1}=0 \mathrm{~mm}$. 
Figure. 4 shows results of the resonant frequency against the anisotropy ratio $\left(A R=\varepsilon_{x} / \varepsilon_{z}\right)$ for an annular ring microstrip patch printed on single anisotropic layer. The results are obtained for a fixed value of $\varepsilon_{x}$, while the parameter $\varepsilon_{z}$ varies. Results for an isotropic substrate are chosen by setting $A=1$. It can be noted that the resonant frequency increases with the anisotropy ratio. Also, it is also seen that the resonant frequency shifts to a higher frequency as the $\varepsilon_{x}$ parameter value decreases.

\section{Conclusion}

Anisotropic substrate shielding and air gap tuning effects on the resonance characteristics of a microstrip ring structure with uniaxially anisotropic substrate are discussed for different layer anisotropies. Computations show that the air separation can be adjusted to have the maximum operating frequency of the antenna. Extreme care should be taken when designing a microstrip antenna with thin air gap; since small uncertainty in adjusting the air separation can result in an important detuning of the frequency.

Unlike ring microstrip antennas without air gaps, changes in the relative permittivity $\varepsilon_{x}$ can significantly shift the resonant frequency of the tunable ring microstrip patch. This means that important errors may arise in the computation of resonant frequencies of microstrip antennas with air gaps if substrate anisotropy is neglected. The results of the study will also be useful in the microstrip ring design using uniaxial metamaterials.

\section{References}

[1] L. Djouablia, I. Messoudan, and A. Benghalia, Uniaxial anisotropic substrate effect on the resonance of an equitriangular microstrip patch antenna, Progress In Electromagnetics reaserch $M$, vol.24, 45-56, 2012.

[2] I. J. Bahl, S. Stuchly, and M. A. Stuchly, A new microstrip radiator for medical applications, IEEE Trans. Microwave Theory Tech., Vol. 28, No. 12, Dec. 1980.

[3] J.-S. Row , Dual-frequency circularly polarised annular-ring microstrip antenna, Electron. Lett., Vol. 40, No. 3, Feb. 2004.

[4] J. Gomez-Tagle, and C. G. Christodoulou, Extended cavity model analysis of stacked microstrip ring antenna, IEEE Trans. Antennas Propagat., Vol. 45, No. 11, Nov. 1997.

[5] S. M. Ali, W. C. Chew, and J. A. Kong, Vector hankel transform analysis of annular-ring microstrip antenna, IEEE Trans. Antennas Propagat., Vol. 30, 637-644, Jul. 1982.

[6] Y. S. Wu, and F. J. Rosenbaum, Mode chart for microstrip ring resonators, IEEE Trans. Microwave Theory Tech., Jul. 1973.

[7] O. Barkat, and A. Benghalia, Radiation and resonant frequency of superconducting annular ring microstrip antenna on uniaxial anisotropic media, Journal of
Infrared, Millimeter and Terahertz, Vol. 30, No. 10, 1053-1066, Jun. 2009.

[8] G. S. Gurel, and E. Yazgan, Resonance in microstrip ring resonator with uniaxially anisotropic substrate and superstrate layers, Journal of Electromagnetic Waves and Applications., Vol. 4, No. 8-9, 1135-1144, 2010.

[9] S. G. Silva, J. R. S. Oliveira., and A. G. Dassuno, Annular ring microstrip antennas for millimeter wave applications, Int.Journal of Infrared and Millimeter Waves., 821-829, Apr. 2007.

[10] I. J. Bahl, and P. Bhartia, Microstrip Antennas, Chap. 3. Artech House, Dedham, MA, 1982.

[11] J. R. James, and P. S. Hall (Eds.), Handbook of Microstrip Antennas., Peter Peregrinus, London, UK, 1989.

[12] A. Bhattacharyya, and R. Garg, Analysis of Annular Ring Microstrip Antenna Using Cavity Model, Arch. Elek. Ubertragung 39, 185-189 1985.

[13] A. K. Bhattacharyya, and R. Garg, Input Impedance of Annular Ring Microstrip Antenna Using Circuit Theory Approach, IEEE Trans. on Antennas and Propagation AP-33, 3369-374 1985.

[14] W. C. Chew, A Broad-Band Annular Ring Microstrip Antenna, IEEE Trans. on Antennas and Propagation AP-30, 918-922 1982.

[15] K. F. Lee, and J. S. Dahele, The two-layered annular ring microstrip antenna, Int. J. Electron., pp. 207217, 1986.

[16] G. Kompa, R. Mehran,Planar Wave guide Model for Calculating Microstrip Components, Electron.Lett.,vol.11,pp.459-460, 1975.

[17] Y. S. Wu, Rosenbaum. Mode chart for microstripring resonators, IEEE Trans ,MTT-21,pp.487-489, 1973.

[18] Y. Tighilt, F. Bouttout, and A. Khellaf, Modeling and Design of Printed Antennas Using Neural Networks, Int $J R F$ and Microwave CAE 21:228-233, 2011.

[19] F. Bouttout, F. Benabdelaziz, A. Benghalia, D. Khedrouche, T. Fortaki, Uniaxially anisotropic substrate effects on resonance of rectangular microstrip patch antenna, Electron. Lett. 35: 255256, 1999.

[20] K. F. Lee, and J. S. Dahele, Theory and experiment on the annular-ring microstrip antenna, ANN.TéLécommun 40, $\mathrm{n}{ }^{\circ} 9-10,1985$. 